\title{
Exploration of the Teaching of Digital Illustration Course
}

\author{
Shu Zhou \\ School of Art \& Design \\ Xi'an University of Technology \\ Xi'an, China 710068
}

\author{
Jie'en Guo \\ School of Art \& Design \\ Xi'an University of Technology \\ Xi'an, China 710068
}

\begin{abstract}
With the advancement of digital technology and the rapid development of digital graphic business demand, the courses of art majors pay more and more attention to the arrangement of digital illustration courses. As a connection course between basic courses and professional courses, as well as a practical consideration in the employment of students, we should pay attention to cultivating students to understand the commercial illustration market, deeply grasp and flexibly use various software technologies, grow rapidly in actual project needs and mainstream style learning, master the learning method and continue the development of art, which is the key points of this course in practical teaching.
\end{abstract}

Keywords—digital illustration; teaching; focus

\section{INTRODUCTION}

With the expansion of the commercial needs of digital illustrations and the development of digital technology, art majors in many colleges have offered courses such as commercial illustrations and digital illustrations, and some universities have set up new majors. The commercial application of illustrations is becoming wider and wider, and the emerging digital technology updates are changing with each passing day. As such a traditional art professional course with the characteristic of new era, it has strong practicality and high speed of knowledge update frequency, so it is inevitable to face with more problems in the teaching process. In order to mobilize the students' enthusiasm for learning and achieve better teaching results, we should give guidance the students mainly from the following aspects in practice:

\section{THE APPLICATION VALUE OF DigITAL ILLUSTRATION COURSE}

At the beginning of the course, we should fully introduce the development background of illustrations, the current state of social needs and the relationship between digital illustrations and other professional courses. Digital illustrations are also a core qualifications and bridges in the current curriculum. This course cultivate professional courses for illustration art talents who are familiar with the design process and can independently design and create; at the same time, it is the bridges and links between professional basic courses (preceding courses such as sketch, color, graphic creativity, etc.) and professional design courses (follow-up course including advertising, packaging, and book binding), which provide the basis of illustration and image for the follow-up courses. The digital illustrations are also one of the courses for the qualification examinations such as animator, advertising designers, and illustrators. Therefore, it becomes the only way to talent market.

From the professional market, the occupations corresponding to the digital illustration course are commercial illustrators. Beginners can do wire draft production, color drafting and other junior work. When they have solid design, styling and performance skills, they can do high-income work of emerging fashion such as commercial illustrators or original game artists. According to the results of the statistics survey, since 2000, more than $80 \%$ of the graduates who have served as the lead artist in large companies have been engaged in various forms of illustration and part-time work during the university. Just part-time job has brought such amazing training to their styling ability. The cultivation of illustration skills is not only the basic training of visual communication and animation, but also the professional skills foundation required by a job.

With the increasing emphasis on the professional training and employment needs of art students, the digital illustration class has become a specialized course that colleges and universities pay more attention to in the art curriculum. Students can fully understand the application value of the course, mobilize their enthusiasm for learning, and know the purpose of learning and the direction of homework research, etc., which will greatly promote the subsequent practical teaching.

\section{THE NECESSITY OF TAKING TECHNICAL LEARNING AS THE BASIS}

Students should have a certain foundation of software technology before this course, but according to the needs of the illustration course, they must further study and emphasize its importance. The importance of technical learning has two aspects. One is because the main tool of modern illustrations must be mastered. Second, in the learning of various software technologies, student can break through the progressive rhythm of traditional painting, and becomes a professionally needed painter who can create more mature commercial works. For the modern information society, it also undoubtedly has practical significance. 
In software learning, Adobe's Illustrator, Flash MX and Corel's CorelDraw are the leaders in many vector graphics design software. Most of the vector software draws a flat decorative image, but using the mesh tool of vector software also has a good expressive power in super-realistic rendering. The picture features are delicate and perfect, not inferior to the effect of digital photography. In comparison, Photoshop and Painter software that is commonly used in bitmap mode drawing, and the digital tablet has a more convenient and quick operation feeling in the performance of the picture, and it is easier for students with a certain drawing foundation to adapt to such a painting method. Students can familiarize themselves with the effects of about 500 kinds of brush strokes, such as oil paintings, pencils, and watercolors. They use digital devices such as a tablet and a pressure sensitive pen to control the transparency, dryness and wetness of the brush strokes. Different software has their own strengths in digital illustrations. For students who have difficulty getting started, they will also be recommended to apply the software ART Rage2 which is good at drawing sketching software, Open Canvas which is good at drawing sketches, and Sai which is more convenient to draw lines. Such small software with clear functions is easy to use, making it easier for beginners to find confidence. In addition, it pays attention to the human body structure and 3Dmax, MAYA, Rhino 3D, and Poser are used to present 3D texture picture. When drawing comics, student can choose tools like Comicstudio to do more with less. The learning of these software technologies greatly exceeds the requirements of the software foundation course. It should be said that according to the situation of each classmate, it is necessary to have a broader understanding of the characteristics of each tool and the targeted and in-depth application.

Because the space of technical support for the visual effects of digital illustrations is extremely large, almost any art form or light-shadow relationship can be imitated, simulated or re-created, driving the creation of digital illustrations to present more fantasy and virtuality, and letting the fantasy picture seems to have an infinitely realistic visual experience, which is also a very exciting point for students. For example, the students are led to use 3D technology to simulate the movement of the characters, or to simulate the effects of various materials, and then make reference and draw, so that many light and shadow relationships and structural relationships are scientific and accurate to avoid insufficient dynamic structure foundation of most students. It is also the perfect combination of science and art that leads students to present more perfect visual performance, which will enhance students' confidence in creation.

In short, the current commercial illustration application requires the work completed at a higher speed with high efficiency and rich screen pictures, so that it is easy to adjust and modify and easy to transfer. Only mastering various kinds of digital software can support it, which is also the help that software tools offer to the application users. Only by encouraging students to master rich technical skills can they express their creative ideas.

\section{STYle LEARNING DRIVES THE WORK TO MATURE QUICKLY}

Under the demand of large and fast information dissemination in the commercial field, digital illustration art has a good cooperation trend with it, which also makes the audiences of digital illustrations wider, and promotes the speed of digital illustrations in the art form and style innovation. Therefore, the digital illustrations of fashion and trend are always the main body of the illustration field, and the charm of modern commercial digital illustrations.

In the digital illustration course, students are allowed to learn and understand some of the mainstream expression styles in commercial illustrations, and then the requirements of actual work projects or competition projects are introduced. We can recommend them to learn the corresponding software tools to conduct design training according to the creative styles and themes chosen by the students. Students with weak structural skills are encouraged to practice vector painting and draw more mature and perfect works with patience and careful decorative language. Students with better realistic ability are encouraged to practice animation design, and classmates who are interested in traditional painting forms can use the software to simulate the work of painting texture. We should combine a variety of peripheral digital devices to collect wide range of materials, use appropriate tools and their various functions to create digital works, and experience the convenience of creative modification and repetitive labor reduction, to maximize the drawing creative inspiration.

In the teaching of digital illustrations, it is found that some problems need to be avoided. First is excessive imitation. The process of learning and imitating is confused with the plagiarism, and there is no self-understanding and thinking. In fact, for the study of art, it is necessary to go through the process of copying, sketching, imitating and innovating, but the convenient technology of digital art, such as its method of copying, mapping, reshaping, etc. is very easy to learn, which makes some students tend to have the bad atmosphere of "copinism". Second, the process of copying and sketching required for learning has deterred many students from avoiding "plagiarism". In the process of digital illustration learning, students should be encouraged to use various methods to try to copy, depict, and sketch and try to figure out the performance techniques and style performance in practice, which not only improves the tool application ability but also learns the artistic expression skills However, it is emphasized that in formal commercial works, people should not copy or plagiarize other people's works. Referring and learning are not plagiarism. In the end, students should be encouraged to express their own creative works in a way that suits their own performance, so that their digital art creation has value. For example, the homework for the second week is assigned after the completion of copying work in the first week. Firstly, teachers help students analyze the style characteristics of copying works, including decorative techniques, color applications, etc., and in-depth discussion and understanding will enable students to quickly find performance ideas and select appropriate reference objects or models in the creation to make a series of 
associations; finally, they can guide students to complete a series of creative assignments that are close to the style of the work they copy. In this process, students learn performance skills on the one hand and understand the creative process on the other hand from no basis of illustration creation to completion of work and the fast entry of the work. The figure is also directly used for fashion magazines, which is no doubt a great inspiration for students to learn illustrations.

\section{ADHERING TO ARTISTRY IS THE DIRECTION OF CONTINUOUS DEVELOPMENT}

For digital illustrations, technical conditions may reduce the requirements for students' drawing skills, but the requirements of mature works in society are also rapidly improved. In addition to the performance of technical skills, the accuracy, perfection, and ideological reflection become a higher pursuit. After the students mastered some tools and software, many works will have a leap, but they cannot become passive users of technology. This makes many students' work level stagnant, and they also find that they need to supplement many painting foundation training to make their creations smoother. If they pursue the maturity of the work and have unique artistic charm, they will face the permanent problem in art creation - the improvement of artistic thought and quality. This task is a long way in the students' learning practice, as well as a process of gradual maturity with personal maturity. For many students, it is easy to ignore such pursuits, so it is necessary to pay attention to let students understand the accumulation of artistic creation to lead a larger space.

To create a good digital illustration work, we need to understand the object and then give it your own feelings and understanding. This is the process of refining the students' artistic thoughts. In the creation of digital illustration art, we can't tend to pursuit shortcuts and utility and confuse the pursuit of creation because of the convenient use of technical skills, which is presented as using a variety of fashion elements, gorgeous elements, concepts of elements without thinking Used. Such works have become a stacking of form, impetuous and lacking artistic charm. To avoid such problems, and to adhere to the continuous development of artistic creation, students must understand that they cannot chase too many "techniques" as in the initial technical study. This is a process that requires a lot of effort to explore and ponder. When you invest more energy and work harder, you will find more in-depth understanding of things while accumulating deeper understanding of things and more expressing ideas will be brought into the work, and these artistic ideas gradually become the vitality of the works. In the mature digital illustration art creation works, the artistic thought is the soul of the work, and the performance skill is the flesh and blood of the work, which cannot be missing in both aspects. No matter how the technology develops, digital illustration art will pay more attention to the realization of creativity. How can we understand art and how should we think; we can cultivate the artistic conception at the spiritual level, and pay attention to the scientific spirit, humanistic quality and the ability to cultivate artistic innovation. These goals should be the common pursuit of any artistic creation.

\section{CONCLUSION}

The above four aspects are some reflections and summaries after the author participated in the teaching of commercial digital illustrations. In the teaching of art students in comprehensive colleges and universities, the basic foundation of students is slightly weak. The creation guidance of digital illustrations pays more attention to steps analysis. For guide methods, they will increase the network communication after class, share resources, visit online related site forums, etc., and they will also consider the career development needs of students. The author hopes that the art market can cultivate more talents in the practical application of such courses.

\section{REFERENCES}

[1] Yin Dingbang. Graphics and Significance [M]. Hunan science and Technology Press, 2001.

[2] Chen Wei. Opinion on the status quo of animation education in colleges and universities in China [J]. China Education Innovation Heral, 2009, 14.

[3] Yu Bingru. Exploration of the Teaching Design of Digital Illustrator Course Based on Work Process[J]. Journal of Literature and Art, 2010,13 